\title{
A CFD-Compatible Amplification Factor Transport Equation for Oblique Tollmien-Schlichting Waves in Supersonic Boundary Layers
}

\author{
JiaKuan Xu $\mathbb{D}^{1},{ }^{1}$ Lei Qiao, ${ }^{2}$ and Junqiang Bai $\mathbb{D}^{2}$ \\ ${ }^{1}$ Department of Mathematics, Imperial College London, SW7 2AZ, UK \\ ${ }^{2}$ School of Aeronautics, Northwestern Polytechnical University, 710072, China \\ Correspondence should be addressed to Junqiang Bai; junqiang@nwpu.edu.cn
}

Received 28 November 2019; Revised 12 February 2020; Accepted 18 February 2020; Published 14 March 2020

Academic Editor: Antonio Viviani

Copyright () 2020 JiaKuan Xu et al. This is an open access article distributed under the Creative Commons Attribution License, which permits unrestricted use, distribution, and reproduction in any medium, provided the original work is properly cited.

\begin{abstract}
Boundary layer transition is a hot research topic in fluid mechanics and aerospace engineering. In low-speed flows, twodimensional Tollmien-Schlichting (T-S) waves always dominate the flow instability, which has been modeled by Coder and Maughmer from 2013. However, in supersonic flows, three-dimensional oblique Tollmien-Schlichting waves become dominant in flow instability. Inspired by Coder and Maughmer's $N_{\mathrm{TS}}$ amplification factor transport equation for twodimensional Tollmien-Schlichting waves in low-speed flows and Kroo and Sturdza's linear stability theory (LST) analysis results for oblique Tollmien-Schlichting waves in supersonic flows, a new amplification factor transport equation for oblique Tollmien-Schlichting waves has been developed based on LST. The compressible Falkner-Skan similarity equations are introduced to build the relationships between nonlocal variables and local variables so that all the variables used in the present model can be calculated using local variables. Applications of this new transport equation to the flows over supersonic flat plate, $3 \%$ thick biconvex airfoil, and one modified supersonic laminar airfoil show promising results compared with the standard LST analysis results.
\end{abstract}

\section{Introduction}

Since laminar flow has less drag than turbulent flow, laminar flow design technology has been a research hotspot in energy conservation of the green aviation [1]. In the process of laminar flow design, the accuracy of transition prediction plays a crucial role on the design effect. Therefore, it is very important and meaningful for aircraft designers to pay close attention to smart and efficient transition prediction methods. In recent years, there are two main routes to predict transition for airplanes and other complex aerodynamic configurations. One is the local transition models established by experimental data and stability analysis results, such as Menter et al.'s $\gamma-\overline{\mathrm{Re}_{\theta t}}$ correlation-based transition model [2-4], Walters et al.'s $k-k_{L}-\omega$ model based on laminar kinetic energy mechanism $[5,6], \mathrm{Fu}$ and Wang's $k-\omega-\gamma$ transition model for high-speed flows [7], and $\mathrm{Xu}$ et al.'s physical mode-based transition models [8-11]. These models play an important role to predict transition for three-dimensional complex aerodynamic flows. The advantages of these transition models are local, convenient, efficient, and compatible with CFD parallel computations. The disadvantage is relying too much on experimental data and empirical parameters.

Compared with the local transition models mentioned above, in the 1950s, a semiempirical method named $e^{N}$ based on linear stability theory, proposed by Smith and Gamberoni [12] and Van Ingen [13], is widely used to predict transition in industry aerodynamic applications [14]. This LSTbased method has been chosen for transition prediction in subsonic and transonic boundary layers by Boeing Inc., Airbus Inc., German Aerospace Center (DLR), National Aeronautics and Space Administration (NASA), France Aerospace Center (ONERA), etc. Subsequently, the $e^{N}$ 
method was simplified by Drela and Giles [15] based on LST analysis results of similarity solutions for laminar flow. This simplified method built the functions between the most unstable amplification factor and the streamwise boundary layer shape factor $H_{12}$, which has been implemented into the famous airfoil design soft " $X$-foil" [16]. With the development of CFD technique, Krimmelbein and Krumbein [17], Bégou et al. [18], Pascal et al. [19], and Shi et al. [20] coupled the LST-based $e^{N}$ method with Reynolds-averaged Navier-Stokes (RANS) code. This kind of coupling is reliable, but it is still complex because it also needs to solve boundary layer equations and linear stability theory equations, to integrate the eigenvalues, and to search nonlocal flow variables at the edge of boundary layers.

Based on Drela's idea, Coder and Maughmer [21] established an amplification factor transport equation to solve the amplification factor based on the approximate envelope method, which was extended using new local pressure gradient parameters $[22,23]$ recently. This transition model can predict the two-dimensional Tollmien-Schlichting (T-S) instabilities and laminar separation bubble- (LSB-) induced transition in low-speed flows. It is worth mentioning that this transport equation for $N_{\text {TS }}$ factor combines the advantages of $e^{N}$ method and local transition models. All the variables in Coder and Maughmer's transport equation can be calculated using local flow variables so that it can be compatible with modern CFD codes conveniently, especially for unstructured codes.

In 2016, Xu et al. [24] constructed a transport equation for amplification factor of crossflow waves, which is restricted to winglike geometries. In 2019, Xu et al. [25] established a local amplification factor transport equation for crossflow instability in low-speed boundary layers, which performs well in several classical transition prediction cases. Hence, it is time to develop this modeling idea to high-speed flows. As known, in subsonic and low-transonic flows, two-dimensional T-S waves dominate the T-S instabilities. However, in supersonic boundary layers, oblique T-S waves play a dominant role [25]. In this paper, we are trying to build a brand new amplification factor transport equation for the oblique T-S waves in supersonic flows. Because the instability mechanism of two-dimensional T-S waves and oblique T-S waves is different, the present transport equation only has the similar form but different content compared with Coder's transport equation. Note that all the nonlocal variables are fitted using the solution database of compressible Falkner-Skan similarity equations. Since a suitable critical value of amplification factor can be found in the flows below Mach number 3.0 using Mack's relations [14, 26, 27] with freestream turbulence intensity, the present work is very valuable and meaningful for natural laminar flow (NLF) optimizations of supersonic airfoils and wings.

\section{Modeling of the Transport Equation}

2.1. Compressible Falkner-Skan Similarity Equations. In order to localize the nonlocal variables, two-dimensional compressible similarity equations are introduced to build the relation functions.

$$
\left\{\begin{array}{l}
\xi=\int_{0}^{x} \rho_{\mathrm{e}} U_{\mathrm{e}} \mu_{\mathrm{e}} d x \\
\eta=\frac{U_{\mathrm{e}}}{\sqrt{2 \xi}} \int_{0}^{y} \rho d y=\sqrt{\frac{\rho_{\mathrm{e}} U_{\mathrm{e}}}{2 \mu_{\mathrm{e}} x}} \int_{0}^{y} \frac{\rho}{\rho_{\mathrm{e}}} d y .
\end{array}\right.
$$

With Illingworth transformation, the two-dimensional boundary equations can be written as [28]

$$
\begin{array}{r}
\left(\frac{\rho \mu}{\rho_{\mathrm{e}} \mu_{\mathrm{e}}} f^{\prime \prime}\right)^{\prime}+f f^{\prime \prime}+\beta_{\mathrm{H}}\left(\frac{\rho_{\mathrm{e}}}{\rho}-f^{\prime 2}\right)=0, \\
\left(\frac{1}{\operatorname{Pr}} \frac{\rho \mu}{\rho_{\mathrm{e}} \mu_{\mathrm{e}}} g^{\prime}\right)^{\prime}+f g^{\prime}+\left(\gamma_{\mathrm{H}}-1\right) M_{\mathrm{e}}^{2} \frac{\rho \mu}{\rho_{\mathrm{e}} \mu_{\mathrm{e}}} f^{\prime \prime 2} \\
+\left(\gamma_{\mathrm{H}}-1\right) M_{\mathrm{e}}^{2} f^{\prime} \beta\left(f^{\prime 2}-g\right)=0,
\end{array}
$$

subject to the boundary conditions

$\eta=0 \longrightarrow f=f^{\prime}=0, g=g_{\mathrm{w}}\left(\right.$ or $g^{\prime}=0$ for adiabatic wall $)$

$\eta=\infty \longrightarrow f^{\prime}=1, g=1$.

In the equations above, $f^{\prime}=u / U_{\mathrm{e}}$ and $g=T / T_{\mathrm{e}}$ indicate the velocity profile and temperature profile, respectively. $\beta_{\mathrm{H}}=\left(2 \xi / U_{\mathrm{e}}\right)\left(d U_{\mathrm{e}} / d \xi\right)$ is the Falkner-Skan pressure gradient parameter, Pr is the Prandtl number, $\gamma_{\mathrm{H}}$ is the ratio of specific heats, $M$ is the Mach number, $\rho$ is the density, and $\mu$ is the dynamic viscosity. Note that the subscript " $e$ " means the variables at the edge of boundary layer.

2.2. Transport Equation Description for Oblique T-S Waves. Firstly, the transport equation takes the form

$$
\begin{aligned}
\frac{\partial\left(\rho N_{\mathrm{TS}}\right)}{\partial t}+\frac{\partial\left(\rho u_{i} N_{\mathrm{TS}}\right)}{\partial x_{i}}= & \rho S F_{\text {crit }} F_{\text {growth }} \frac{d N_{\mathrm{TS}}}{d \operatorname{Re}_{\theta}} \\
& +\frac{\partial}{\partial x_{i}}\left[\left(\mu+\mu_{t}\right) \frac{\partial N_{\mathrm{TS}}}{\partial x_{i}}\right],
\end{aligned}
$$

where $S$ is the strain rate magnitude, $F_{\text {crit }}$ indicates the onset function, $F_{\text {growth }}$ stands for the development function of growth rate, and $d N_{\mathrm{TS}} / d \mathrm{Re}_{\theta}$ represents the slop of the amplification factor $N_{\mathrm{TS}}$ and momentum thickness Reynolds number $\operatorname{Re}_{\theta}$. The source term is mainly established based on the extensive linear stability analysis results by Kroo and Sturdza [29] for oblique T-S waves in supersonic flows. The details can be found in Ref. [29].

Secondly, the onset function, $F_{\text {crit }}$, is given by

$$
F_{\text {crit }}= \begin{cases}0, & \operatorname{Re}_{\theta}<\operatorname{Re}_{\theta, \text { crit }}, \\ 1, & \operatorname{Re}_{\theta} \geq \operatorname{Re}_{\theta, \text { crit }},\end{cases}
$$

where $\operatorname{Re}_{\theta \text {,crit }}$ is the critical momentum thickness Reynolds number with the following expressions [29]: 


$$
\begin{aligned}
\log _{10}\left(\frac{\operatorname{Re}_{\theta, \text { crit }}}{K_{0}^{0.7}}\right)= & \left(\frac{1.415}{H_{\mathrm{k}}-1}-0.489\right) \tanh \left(\frac{20}{H_{\mathrm{k}}-1}-12.9\right) \\
& +\frac{3.295}{H_{\mathrm{k}}-1}+0.44, \\
K_{0}= & \frac{2}{\pi} \tan ^{-1}\left(10 \frac{T_{\mathrm{w}}}{T_{\mathrm{e}}}-10\right)+1, \\
\frac{T_{\mathrm{w}}}{T_{\mathrm{e}}}= & \left(1+\frac{\gamma_{\mathrm{H}}-1}{2} \sqrt{\operatorname{Pr}} M_{\mathrm{e}}^{2}\right) .
\end{aligned}
$$

Here, $H_{\mathrm{k}}$, proposed by Drela and Giles [15] and defined as $H_{\mathrm{k}}=\int\left(1-u / U_{\mathrm{e}}\right) d y / \int\left(1-u / U_{\mathrm{e}}\right) u / U_{\mathrm{e}} d y$, means the kinematic shape parameter.

Thirdly, the function $F_{\text {growth }}$ is similar to Drela and Giles's [15] and Coder and Maughmer's [21] formulations:

$$
F_{\text {growth }}=D\left(H_{\mathrm{k}}\right) \frac{\left[1+m\left(H_{\mathrm{k}}\right) l\left(H_{\mathrm{k}}\right)\right]}{2},
$$

where

$$
\begin{aligned}
D\left(H_{\mathrm{k}}\right) & =\frac{2.775 H_{\mathrm{k}}-2.083}{H_{\mathrm{k}}-1.948}, \\
l\left(H_{\mathrm{k}}\right) & =\frac{6.54 H_{\mathrm{k}}-14.07}{H_{\mathrm{k}}^{2}}, \\
m\left(H_{\mathrm{k}}\right) & =\left[0.058 \frac{\left(H_{\mathrm{k}}-4\right)^{2}}{H_{\mathrm{k}}-1}-0.068\right] \frac{1}{l\left(H_{\mathrm{k}}\right)} .
\end{aligned}
$$

The functions $l\left(H_{\mathrm{k}}\right)$ and $m\left(H_{\mathrm{k}}\right)$ have the same expressions with Drela and Giles's formulations. The $D\left(H_{\mathrm{k}}\right)$ correlation is developed to modify the behavior of the source term at various kinematic shape parameters through lots of calibrations.

Fourthly, the slope function is modeled as

$$
\begin{aligned}
\frac{d N_{\mathrm{TS}}}{d \mathrm{Re}_{\theta}}= & \frac{0.01 K_{1}}{K_{\mathrm{b}}}\left\{\left[2.4 H_{\mathrm{k}} K_{\mathrm{a}}-3.7+2.5 K_{\mathrm{c}} \tanh \left(1.5 H_{\mathrm{k}}-4.65\right)\right]^{2}\right. \\
& \left.+0.125+K_{\mathrm{d}}-K_{\mathrm{m}}\right\} \\
K_{1}= & 0.5463\left(0.4811 \frac{T_{\mathrm{w}}}{T_{\mathrm{e}}}+1\right) \\
K_{\mathrm{a}}= & 1+0.2\left(H_{\mathrm{k}}-2.5918\right)\left(1-\frac{T_{\mathrm{e}}}{T_{\mathrm{w}}}\right) \\
K_{\mathrm{b}}= & 4.7\left(\frac{T_{\mathrm{w}}}{T_{\mathrm{e}}}-1\right)+1 \\
K_{\mathrm{c}}= & \frac{T_{\mathrm{w}}}{T_{\mathrm{e}}} \\
K_{\mathrm{d}}= & 1.2\left(\frac{T_{\mathrm{w}}}{T_{\mathrm{e}}}-1\right)^{3 / 2}
\end{aligned}
$$

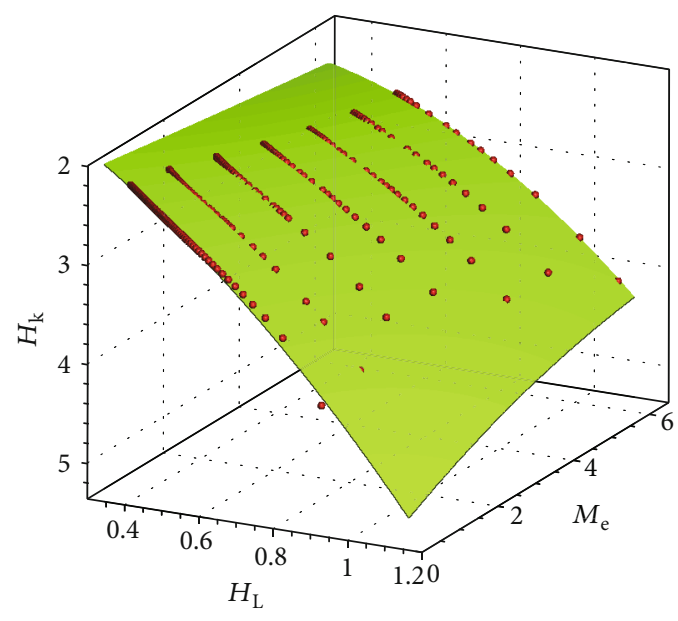

Figure 1: Relations among $M_{\mathrm{e}}, H_{\mathrm{L}}$, and $H_{\mathrm{k}}$.

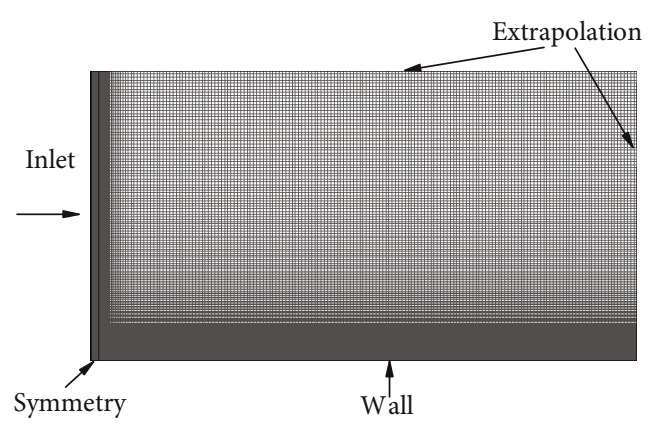

Figure 2: CFD mesh and boundary conditions.

where $K_{1}, K_{\mathrm{a}}, K_{\mathrm{b}}, K_{\mathrm{c}}$, and $K_{\mathrm{d}}$ are all the compressibility correction coefficients and $T_{\mathrm{w}}$ is the wall temperature. It is worth mentioning that $K_{\mathrm{m}}$ means the history effect. Kroo and Sturdza use $K_{\mathrm{m}}=11.5 \sqrt{T_{\mathrm{w}} / T_{\mathrm{e}}}\left(H_{\mathrm{k}_{\mathrm{a}} \text { avg }}-H_{\mathrm{k}}\right)$ and $H_{\mathrm{k} \_ \text {avg }}=\left(1 / s-s_{0}\right) \int_{s_{0}}^{s} H_{\mathrm{k}} d s$ to calculate $K_{\mathrm{m}}$, which is very difficult to compute using local variables. For the integral, transport equation with additional source term can be applied. However, it seems very difficult to compute the average of upstream parameter $H_{\mathrm{k}}$ using local variables. Therefore, in this paper, the history effect term is set as zero temporarily and this term will be developed in the next step.

Not only two-dimensional T-S waves but also threedimensional oblique T-S waves are stabilized by favorable pressure gradient and increase near the adverse pressure gradient region. It should be mentioned that the $H_{\mathrm{k}}$ ranges from 2.5 to 3.0 for these formulations above, which means this transport equation can only be used to describe the development of pure oblique T-S waves in the supersonic flows with moderate favorable pressure gradient and adverse pressure gradient. For the flows with strong favorable pressure gradient, like the stagnation point flows around blunt leading edge, subsonic regions always appear so that $H_{\mathrm{k}}$ exceeds the current modeling scope. The present model cannot predict the two-dimensional T-S waves which are different from the oblique T-S waves. 


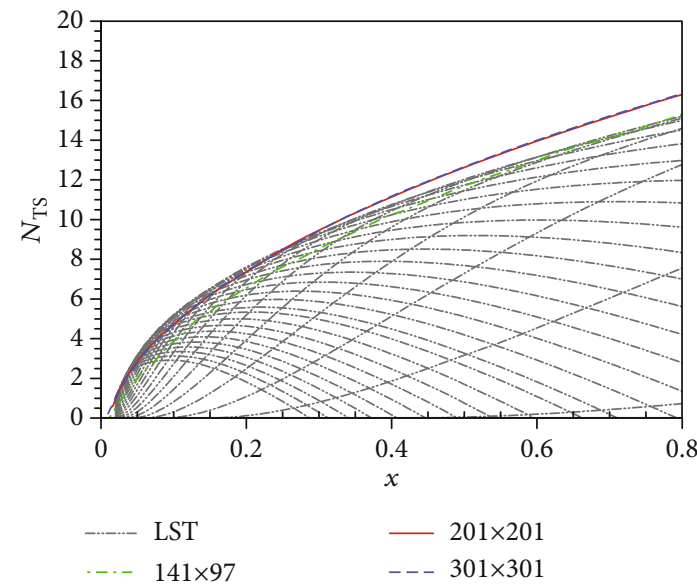

(a)

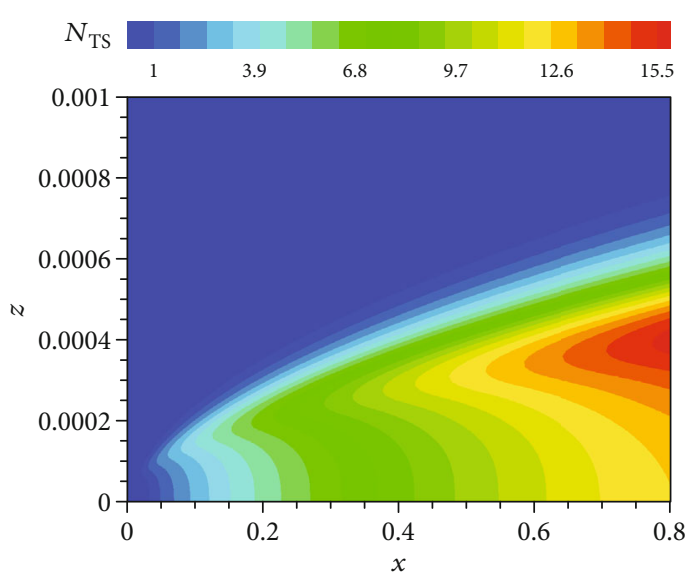

(b)

Figure 3: Predicted results of amplification factor. (a) Comparison with standard LST analysis results. (b) Contour at Mach number $=2.2$ and Reynolds number $=5.6 \times 10^{7} / \mathrm{m}$.

Fifthly, after filtering the existing parameters to describe the pressure gradient, the local parameter $H_{\mathrm{L}}=S y / U_{\mathrm{e}}$, proposed by Coder and Maughmer [21], was adopted to calculate the kinematic shape parameter $H_{\mathrm{k}}$. In the definition, $y$ is the distance to the nearest wall. Figure 1 plots the function among Mach number $M_{\mathrm{e}}, H_{\mathrm{L}}$, and $H_{\mathrm{k}}$, which is obtained by similarity solutions and can be formulated as

$$
\begin{aligned}
H_{\mathrm{k}}= & 1.261+0.2083 M_{\mathrm{e}}-0.006437 M_{\mathrm{e}}^{2}-0.00006606 M_{\mathrm{e}}^{3} \\
& +0.0184 M_{\mathrm{e}}^{2} H_{\mathrm{L}}+0.06087 M_{\mathrm{e}} H_{\mathrm{L}}^{2}-0.449 M_{\mathrm{e}} H_{\mathrm{L}} \\
& +1.407 H_{\mathrm{L}}^{2}+1.658 H_{\mathrm{L}} .
\end{aligned}
$$

Sixthly, Xu et al.'s engineering estimation method [9] for Mach number at the edge of boundary layer is chosen, which has the expressions as follows:

$$
\begin{aligned}
\left(\frac{\gamma_{\mathrm{H}}}{\gamma_{\mathrm{H}}-1}\right) \frac{P_{\infty}}{\rho_{\infty}}+\frac{U_{\infty}^{2}}{2} & =\left(\frac{\gamma_{\mathrm{H}}}{\gamma_{\mathrm{H}}-1}\right) \frac{P}{\rho_{\mathrm{e}}}+\frac{U_{\mathrm{e}}^{2}}{2}, \\
\frac{a_{\infty}^{2}}{\gamma_{\mathrm{H}}-1}+\frac{U_{\infty}^{2}}{2} & =\frac{a_{\mathrm{e}}^{2}}{\gamma_{\mathrm{H}}-1}+\frac{U_{\mathrm{e}}^{2}}{2},
\end{aligned}
$$

where $a$ stands for the sound speed, $P$ is the pressure, and the subscript $\infty$ denotes variables in freestream. Furthermore, $\rho_{\mathrm{e}}$ could be given by $\rho_{\mathrm{e}}=\left[\left(\rho_{\infty}^{\gamma_{\mathrm{H}}} / P_{\infty}\right) P\right]^{1 / \gamma_{\mathrm{H}}}$ and the Mach number at the edge of boundary layer is determined as $M_{\mathrm{e}}=U_{\mathrm{e}} / a_{\mathrm{e}}$. In some nonlocal models, $M_{\mathrm{e}}$ can be obtained through searching operations. However, through the aerodynamic equations (11) and (12), it can get a relatively accurate estimation of $M_{\mathrm{e}}$, which is much more accurate than using the freestream Mach number $M_{\infty}$ directly. It should point out that the prediction of $M_{\mathrm{e}}$ is a CFD issue, which can be computed by the aerodynamic formulations and CFD variables. This part does not belong to the transition modeling content.

Finally, the last unknown parameter is the local momentum thickness Reynolds number $\operatorname{Re}_{\theta}=\rho U_{\mathrm{e}} \theta / \mu$. From the similarity solution database, the relationship between $\operatorname{Re}_{\theta}$ and the vorticity Reynolds number $\operatorname{Re}_{\mathrm{V}}=\rho S y^{2} / \mu$ is described as

$$
\Theta\left(M_{\mathrm{e}}\right)=\frac{\mathrm{Re}_{\mathrm{V}}}{2.193 \operatorname{Re}_{\theta}}=1+\frac{\left(\gamma_{\mathrm{H}}-1\right)}{2} M_{\mathrm{e}}^{2} .
$$

Since there is a small height difference between the maximum value of $\operatorname{Re}_{\mathrm{V}}$ and $H_{\mathrm{L}}$ in favorable pressure gradient boundary layers, a minor height correction is introduced:

$$
\operatorname{Re}_{\theta}=\operatorname{Re}_{\theta}\left[1.086 \exp \left(0.3455 \lambda_{\theta}^{\prime}\right)+0.01279 \exp \left(18.28 \lambda_{\theta}^{\prime}\right)\right] \text {, }
$$

where $\lambda_{\theta}=\left(\rho \theta^{2} / \mu\right)\left(d U_{\mathrm{e}} / d s\right)$ is the Thwaites pressure gradient factor and $\lambda_{\theta}^{\prime}$ can be computed using the following equations $[25,30]$ :

$$
\begin{aligned}
\theta & =\frac{\max \left(d^{2} S\right)}{2.2 U_{\mathrm{e}} \Theta\left(M_{\mathrm{e}}\right)}, \\
\frac{d U_{\mathrm{e}}}{d s} & =\frac{u}{U} \frac{d U_{\mathrm{e}}}{d x}+\frac{v}{U} \frac{d U_{\mathrm{e}}}{d y}+\frac{w}{U} \frac{d U_{\mathrm{e}}}{d z}, \\
\frac{d U_{\mathrm{e}}}{d x_{i}} & =\frac{1}{U_{\mathrm{e}} \rho_{\infty}}\left(\frac{P}{P_{\infty}}\right)^{-1 / \gamma_{\mathrm{H}}} \frac{d P}{d x_{i}}, \\
\lambda_{\theta}^{\prime} & =\lambda_{\theta}\left(1+\frac{\left(\gamma_{\mathrm{H}}-1\right)}{2} M_{\mathrm{e}}^{2}\right) .
\end{aligned}
$$




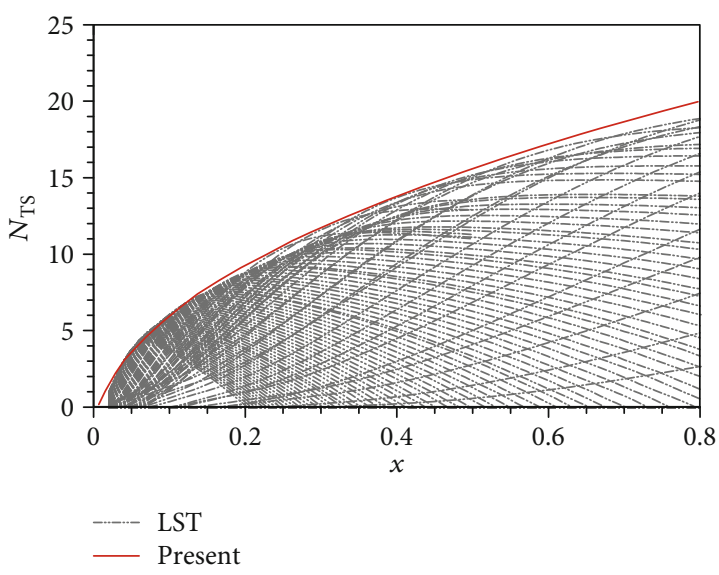

(a)

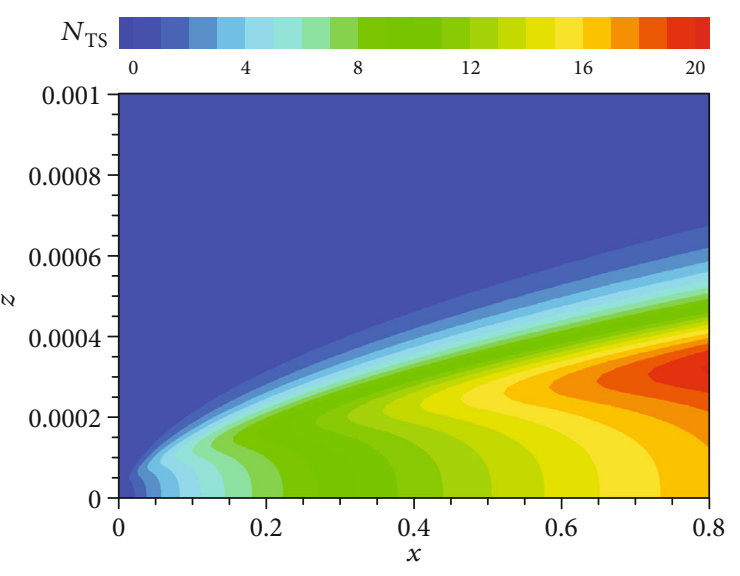

(b)

FIgURE 4: Predicted results of amplification factor. (a) Comparison with standard LST analysis results. (b) Contour at Mach number $=1.5$ and Reynolds number $=5.4 \times 10^{7} / \mathrm{m}$.

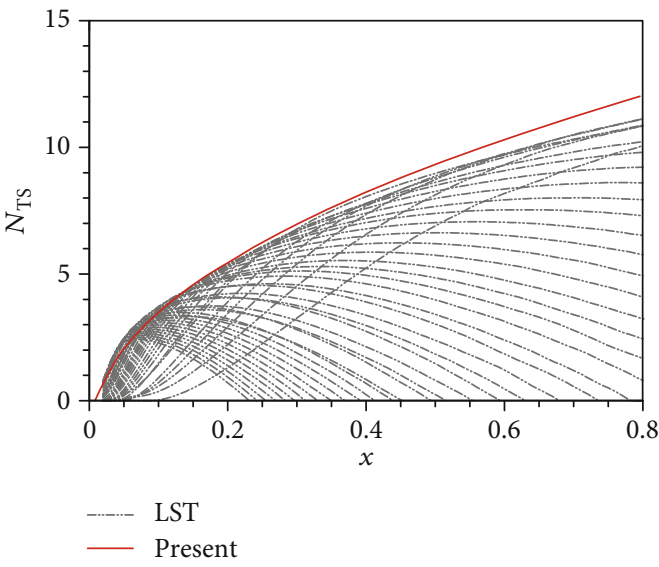

(a)

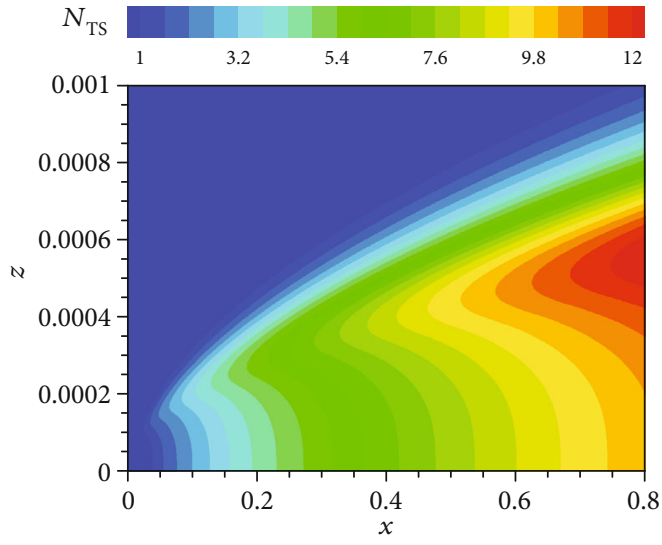

(b)

FIGURE 5: Predicted results of amplification factor. (a) Comparison with standard LST analysis results. (b) Contour at Mach number $=2.2$ and Reynolds number $=3.0 \times 10^{7} / \mathrm{m}$.

Note that the incompressibility correction for $\lambda_{\theta}$ comes from Ref. [31] and $\lambda_{\theta}^{\prime}$ corresponds to the modified Thwaites pressure gradient factor.

Finally, the effective intermittency factor takes the form

$$
\gamma_{\mathrm{eff}}=\max \left\{\gamma, \exp \left[2 \max \left(N_{\mathrm{TS}}-N_{\mathrm{TS}, \text { crit }}\right)\right]\right\},
$$

where $\gamma$ is the intermittency factor and the effective intermittency factor $\gamma_{\text {eff }}$ is used to trigger transition in the turbulence model. The coupling way between the transition model and the Menter's Shear Stress Transport (SST) turbulence model from Coder and Maughmer's paper [32] in 2013 is selected in this paper, which is given by

$$
\begin{aligned}
\frac{\partial(\rho k)}{\partial t}+\frac{\partial\left(\rho u_{i} k\right)}{\partial x_{i}}= & \gamma_{\text {eff }} P_{k, \text { original }} \\
& -\min \left(\max \left(\gamma_{\text {eff }}, 0.1\right), 1.0\right) D_{k, \text { original }} \\
& +\frac{\partial}{\partial x_{i}}\left[\left(\mu+\sigma_{k} \mu_{t}\right) \frac{\partial k}{\partial x_{i}}\right] .
\end{aligned}
$$

Note that $\gamma_{\text {eff }}$ is the switch function for the generation of turbulent kinetic energy by the production term $P_{k, \text { original }}$ and the destruction term $D_{k, \text { original }}$ in the SST turbulence model. For comparison, the saddle point method, proposed by Cebeci and Stewartson [33], is adopted for the standard LST analysis. 


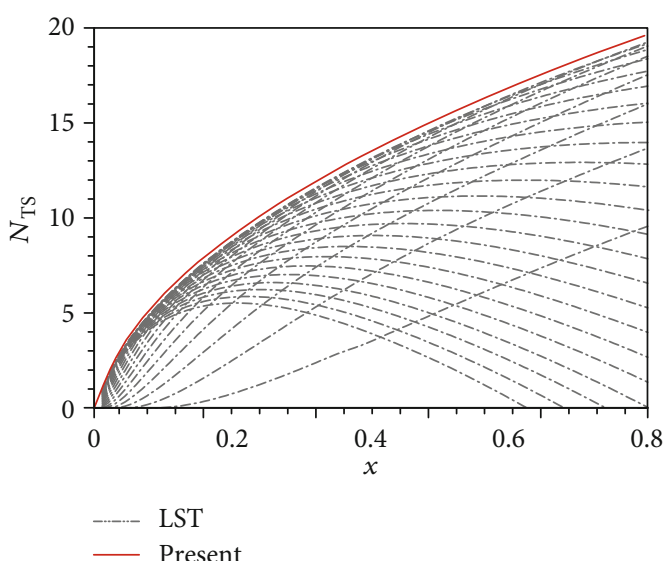

(a)

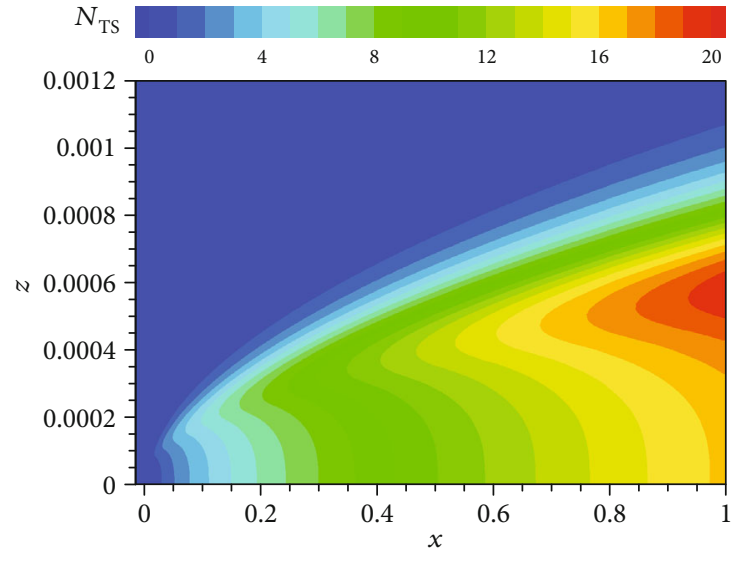

(b)

FIGURE 6: Predicted results of amplification factor. (a) Comparison with standard LST analysis results. (b) Contour at Mach number $=3.0$ and Reynolds number $=5.6 \times 10^{7} / \mathrm{m}$.

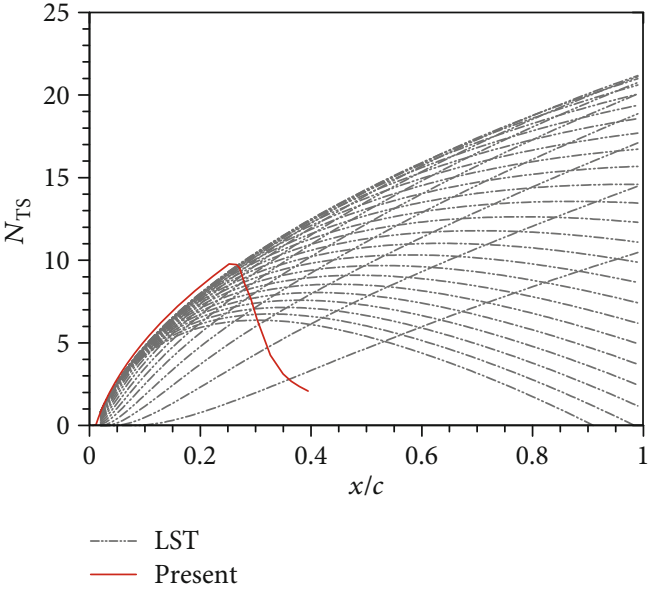

(a)

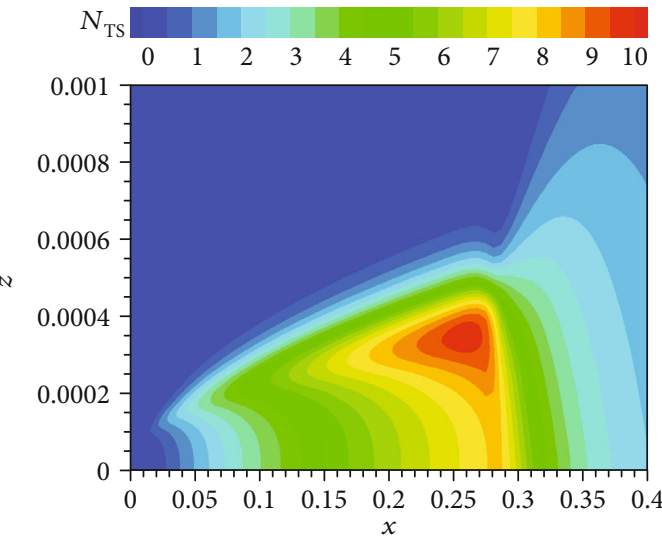

(b)

FIgURE 7: Predicted results of amplification factor (a) Comparison with standard LST analysis results; (b) contour at Mach number = 3.5 and Reynolds number $=5.89 \times 10^{7} / \mathrm{m}$.

\section{Results and Discussion}

In the present work, the open-source structured Reynoldsaveraged Navier-Stokes solver named CFL3D was used as the basic flow solver. Details of this solver could be found in NASA's website (data available online at https://cfl3d.larc .nasa.gov/) and documents [34]. In this work, all of the transition prediction results were obtained by the present transport equation coupling with Menter's $k-\omega$ SST turbulence model.

3.1. Validation Test Case 1: Supersonic Flat Plate. The first case is the zero-pressure-gradient supersonic flat plate. The basic mesh with boundary conditions for the following computations is shown in Figure 2. At first, the $149 \times 97$-point mesh, $201 \times 201$-point mesh, and $301 \times 301$-point mesh are

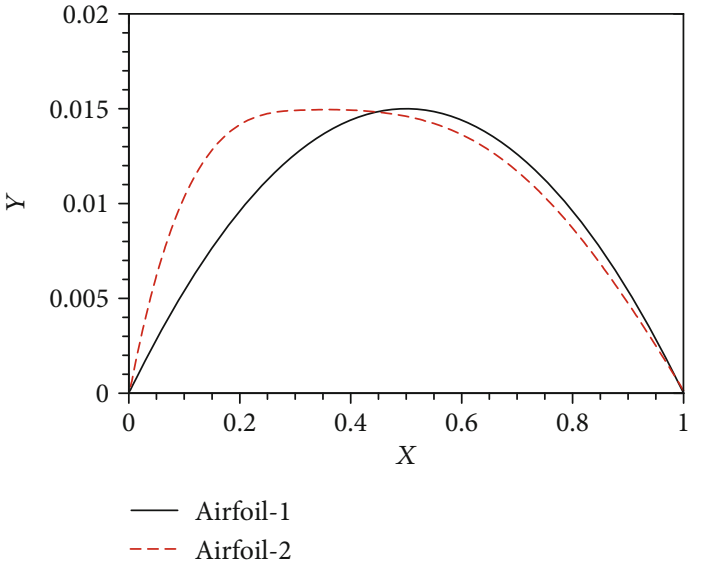

Figure 8: Supersonic airfoils. 


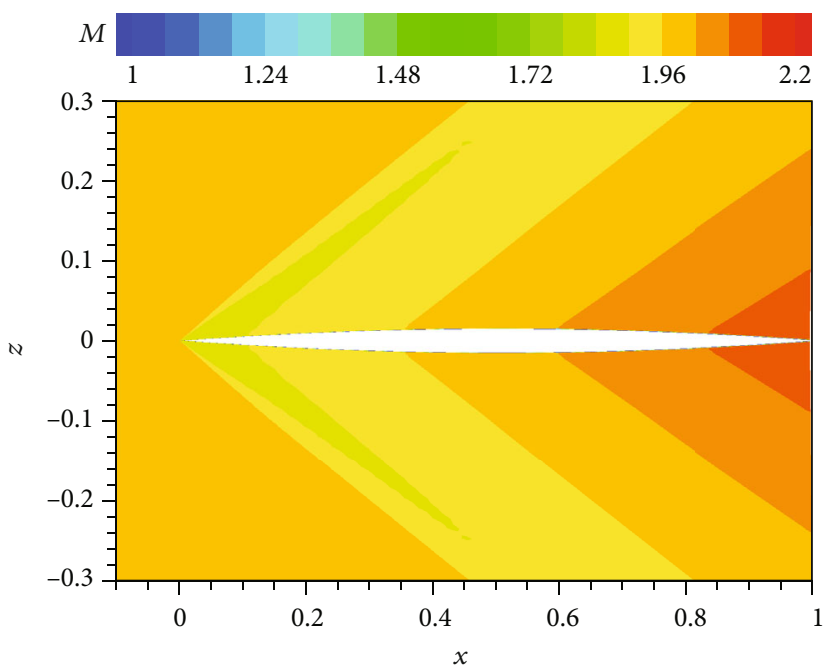

(a)

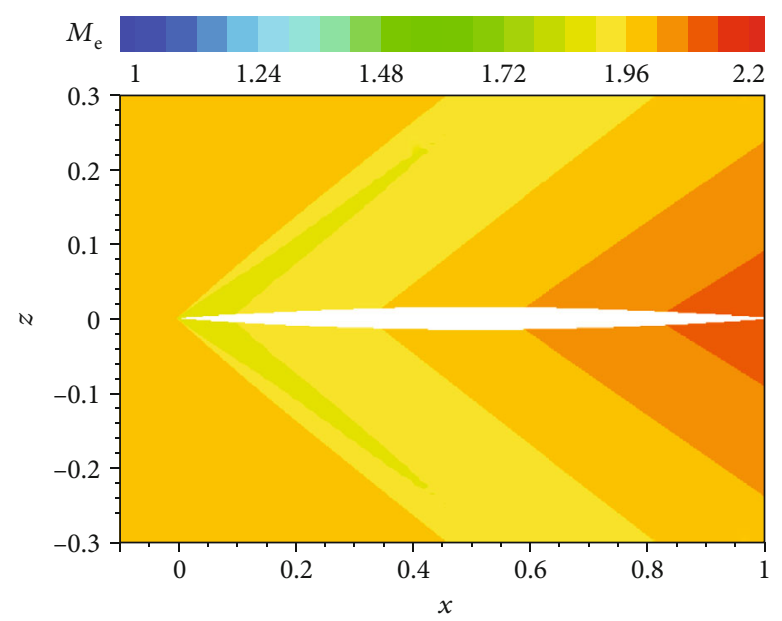

(b)

Figure 9: Comparison between (a) local Mach number and (b) predicted $M_{\mathrm{e}}$ with angle of attack of $0^{\circ}$.

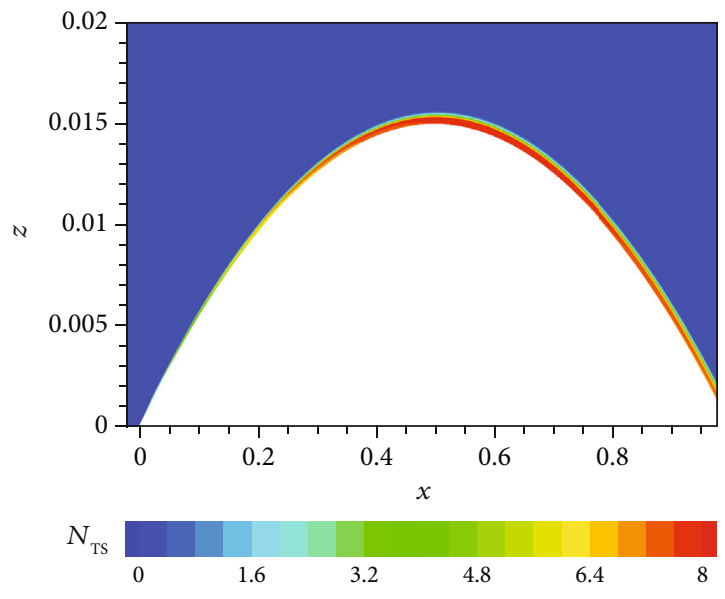

(a)

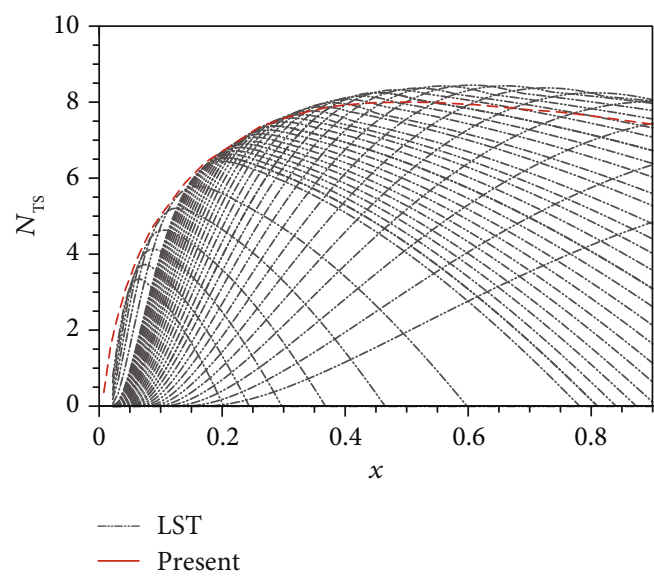

(b)

FIgURE 10: The predicted (a) $N_{\text {TS }}$ contour and (b) comparison with standard LST analysis results when angle of attack is $0^{\circ}$.

employed to conduct the mesh sensitive test, and the results are illustrated in Figure 3(a). The Mach number is 2.2 and Reynolds number is $5.6 \times 10^{7} / \mathrm{m}$. The near-wall mesh is fine enough so that $y^{+}(1)$ of the cell next to the wall is smaller than 1.0. It can be seen that as the amount of the grid increases, the results converge gradually, demonstrating the robustness of the new transport equation. Figure 3(b) displays the contour of $N_{\text {TS }}$ factor calculated by the present transport equation. Note that the predicted maximum value of $N_{\text {TS }}$ factor is extracted from the $N_{\text {TS }}$ contour at each streamwise location. With further validations, various freestream conditions were considered. Figure 4 displays the contour of predicted $N_{\mathrm{TS}}$ factor and the comparison with the standard LST analysis results under the conditions of $M_{\infty}=1.5$ and $\operatorname{Re}=5.4 \times 10^{7} / \mathrm{m}$. Meanwhile, the Mach number is 2.2 in Figure 5 and 3.0 in Figure 6. Moreover, the unit Reynolds number in Figure 5 is $3.0 \times 10^{7} / \mathrm{m}$ and $5.6 \times 10^{7} / \mathrm{m}$ in Figure 6. Although the Mach numbers and Reynolds num- bers change, the predicted results of $N_{\text {TS }}$ factor seem robust and accurate. When a critical value of $N_{\text {TS }}$ factor was set as 10.0 , the results in the case with $M_{\infty}=3.5$ and $\mathrm{Re}=5.89 \times$ $10^{7} / \mathrm{m}$ are plotted in Figure 7. Before the threshold value of $N_{\text {TS }}$ factor, the development of $N_{\text {TS }}$ factor is described accurate and transition occurs near the threshold. Subsequently, in the turbulent region, $N_{\text {TS }}$ factor will be quickly dissipated. As a result, the whole process of oblique T-S wave-induced transition is simulated reasonably.

3.2. Validation Test Case 2: Biconvex Laminar Airfoil. Secondly, the 3\% thick biconvex airfoil, i.e., the "Airfoil-1" as plotted in Figure 8, is chosen for validations. Note that the coordinates of this classical airfoil are formulated as $z / c=0.06 x / c(1-x / c)$. The following airfoil cases use the same topology structure of mesh with the flat plate cases. The freestream conditions are set as $M_{\infty}=2.0$ and $\mathrm{Re}=$ $5.4 \times 10^{7} / \mathrm{m}$. When the angle of attack (AoA) is zero, the 


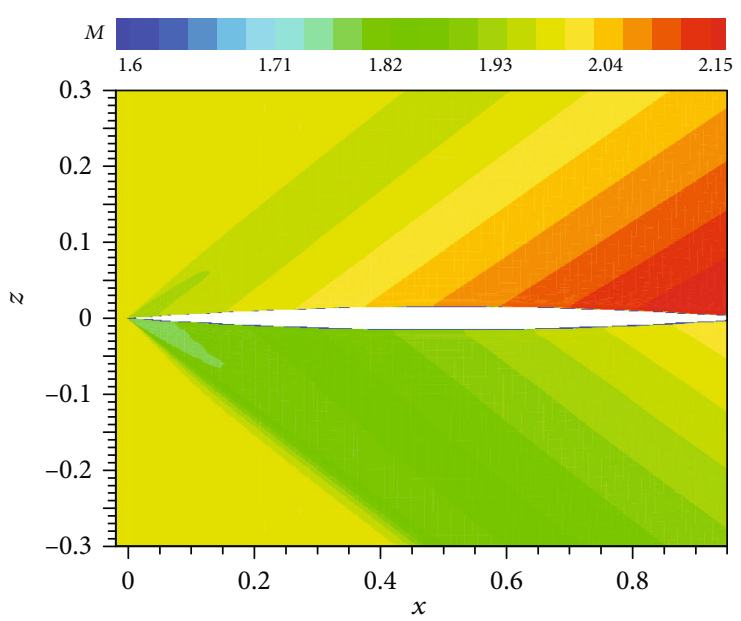

(a)

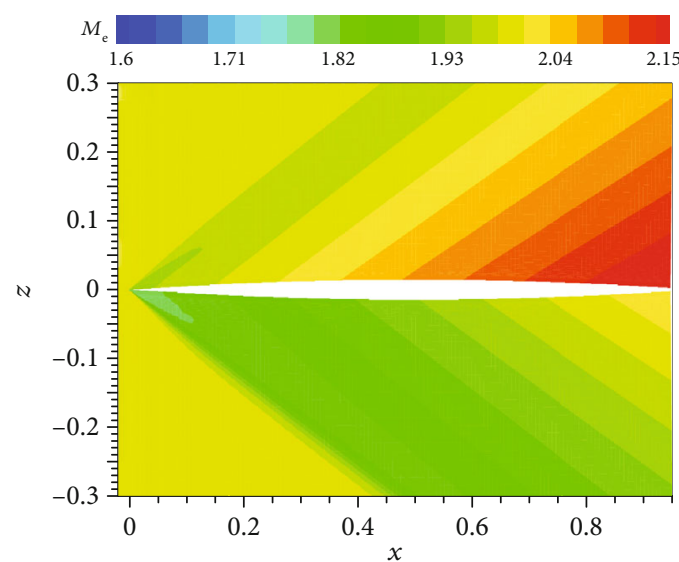

(b)

Figure 11: Comparison between (a) local Mach number and (b) predicted $M_{\mathrm{e}}$ with angle of attack of $2^{\circ}$.

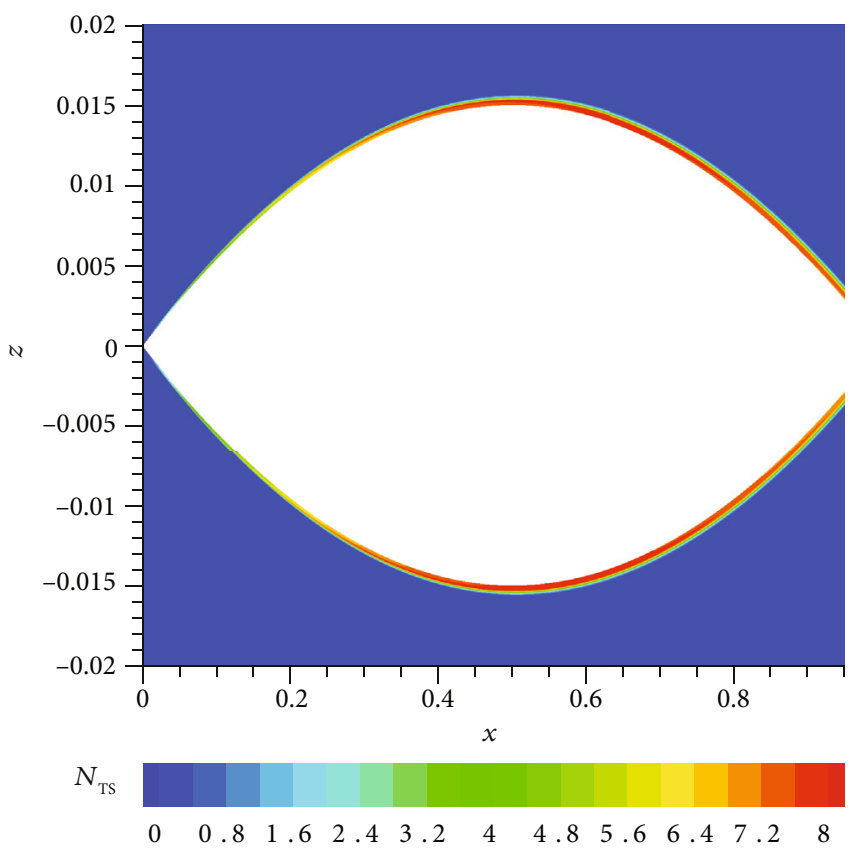

FIgURE 12: The predicted $N_{\text {TS }}$ contour with angle of attack of $2^{\circ}$.

predicted Mach number at the edge of boundary layer is shown in Figure 9, compared with the contour of local Mach number. The predicted value of $M_{\mathrm{e}}$ agrees well with the contour of local Mach number. The calculated $N_{\text {TS }}$ contour and the maximum value at each streamwise location are sketched in Figure 10.

When the angle of attack is 2 degrees, Figure 11 demonstrates the predicted Mach number at the edge of boundary layer which is in accord with the value at the outer edge of the boundary layer in the local Mach number contour. The predicted $N_{\text {TS }}$ contour is displayed in Figure 12. Furthermore, the extracted data on the upper surface and lower surface are plotted in Figures 13(a) and 13(b), respectively. It can be seen that most of the $N_{\text {TS }}$ factor are simulated accurately.
It is worth noting that the defects without history effect term gradually appear downstream. This is the main reason of the deviations between the predicted value and the standard LST results in the downstream region. Certainly, even though the nonlocal methods are used, there are still deviations compared with the standard LST analysis data [18]. Consequently, the small deviations predicted here can be accepted.

3.3. Validation Test Case 3: Modified Laminar Airfoil. The third case for validation is the "Airfoil-2" as shown in Figure 8, which has a larger radius of curvature near the leading edge. The freestream Mach number is 1.8 and the unit Reynolds numbers contain $\operatorname{Re}=3.5 \times 10^{7} / \mathrm{m}, 5.4 \times 10^{7} / \mathrm{m}$, and $8.0 \times 10^{7} / \mathrm{m}$. The estimated $M_{\mathrm{e}}$ is still in good agreement with the reference data 


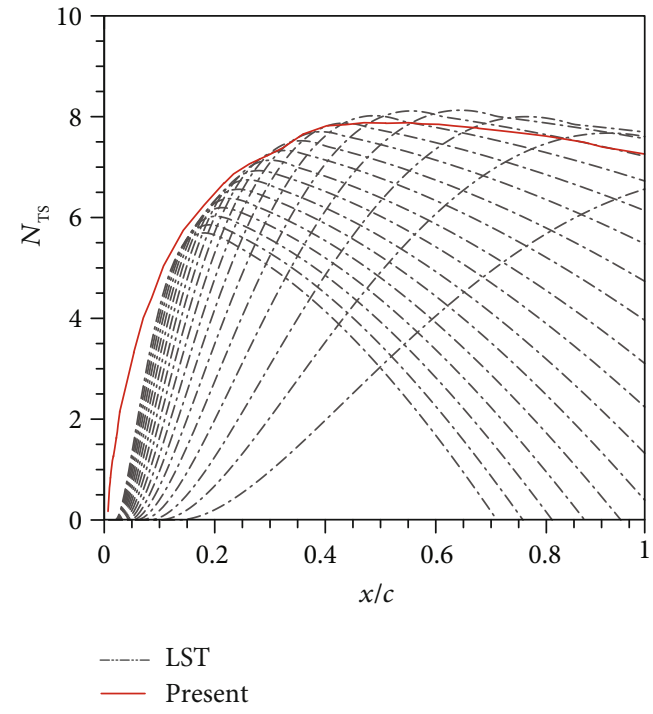

(a)

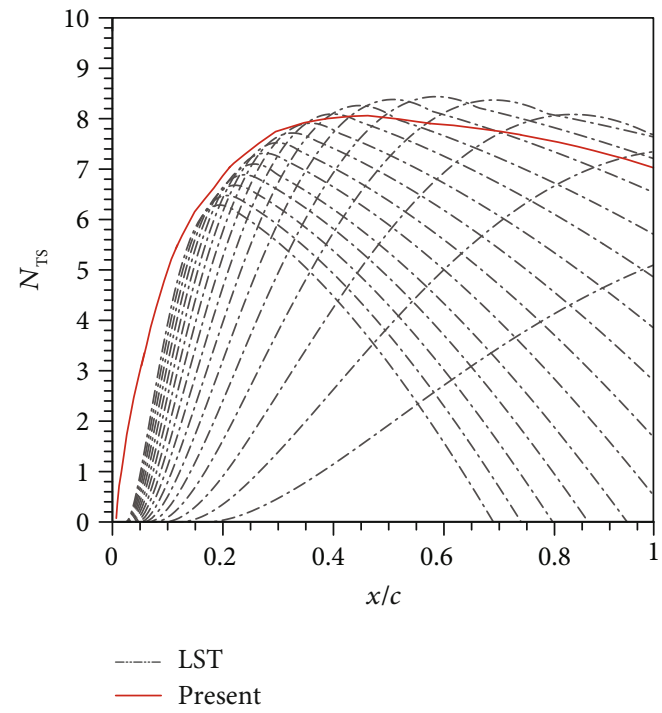

(b)

FIgURE 13: The predicted $N_{\text {TS }}$ factor on the (a) upper surface and (b) lower surface with angle of attack of $2^{\circ}$.

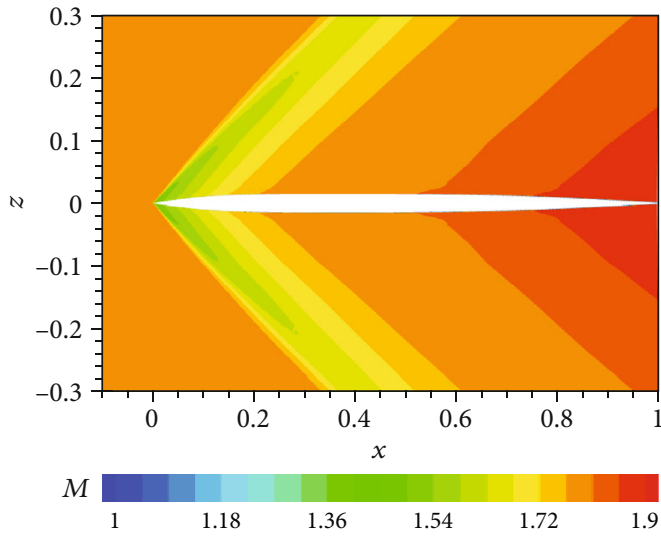

(a)

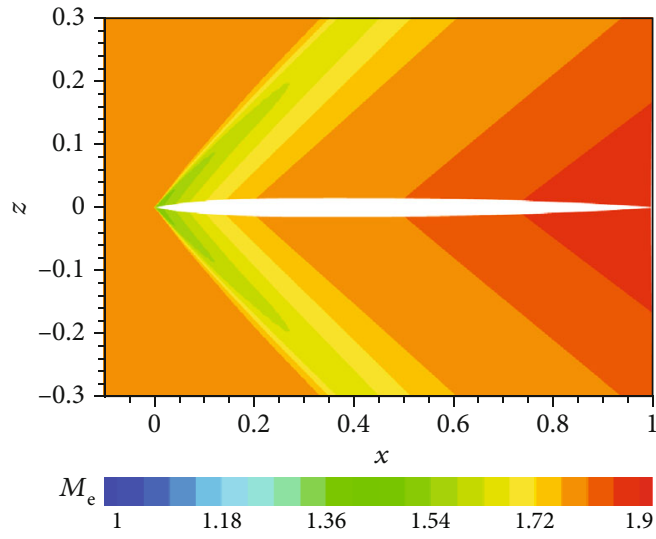

(b)

FIgURE 14: Comparison between (a) local Mach number and (b) predicted $M_{\mathrm{e}}$ with Mach number of 1.8.

shown in Figure 14. In addition, Figures 15-17 illustrate the computed $N_{\text {TS }}$ factor contour and the comparison with standard LST analysis results. Overall, the present transport equation works well. However, due to the lack of history effect term, there are obvious deviations between the predicted value of $N_{\text {TS }}$ and the standard LST results. Therefore, for the computations in moderate or strong favorable pressure gradient flows, it seems quite difficult to compute the average of upstream integrated variables using local variables. This problem will be solved in the future research.

\section{Conclusions}

In summary, a new amplification factor transport equation for the oblique T-S waves in supersonic flows has been developed based on linear stability analysis results and validated in several typical two-dimensional supersonic flows. The good agreement between the present transport equation and the standard LST analysis results in two-dimensional supersonic airfoils which show that the present transport equation is very promising and encouraging. Obviously, this model has the potential to be extended and applied to predict the oblique T-S waves on three-dimensional wings with sharp leading edge and cones with sharp nose. Moreover, crossflow instability, playing an important role in $3 \mathrm{D}$ boundary layers, should be taken into account in the future research.

It should be pointed out that the present model can only simulate the pure oblique T-S waves, which means it cannot predict the airfoils with blunt leading edge. Because there is a subsonic region near the blunt leading edge, the instability mechanism near the leading edge may start from two-dimensional T-S waves to oblique T-S waves. Hence, this complex process cannot be captured using the present model. 


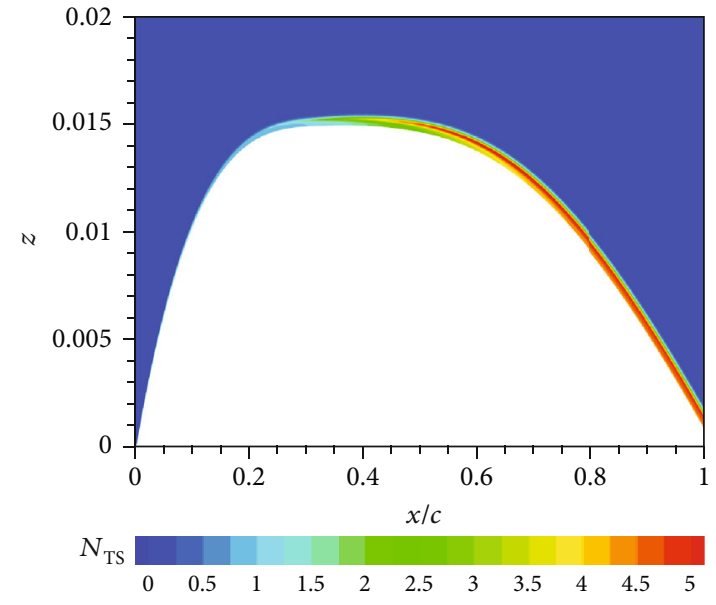

(a)

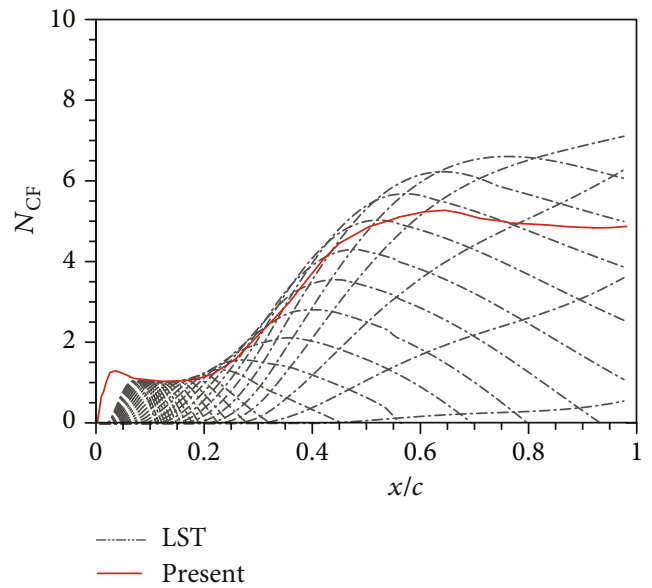

(b)

Figure 15: The predicted (a) $N_{\text {TS }}$ contour and (b) comparison with standard LST analysis results at $\operatorname{Re}=3.5 \times 10^{7} / \mathrm{m}$.

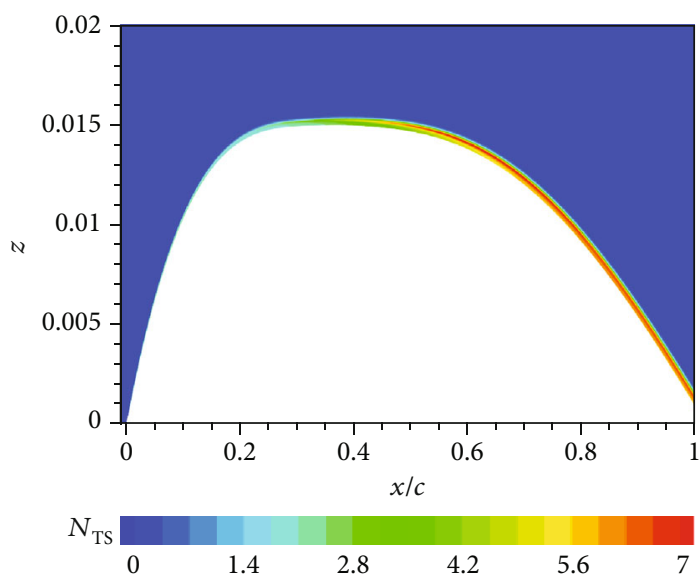

(a)

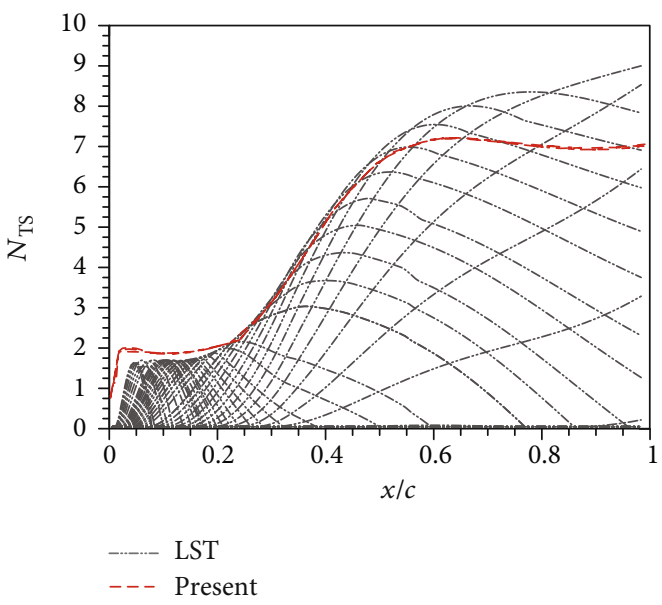

(b)

Figure 16: The predicted (a) $N_{\text {TS }}$ contour and (b) comparison with standard LST analysis results at $\operatorname{Re}=5.4 \times 10^{7} / \mathrm{m}$.

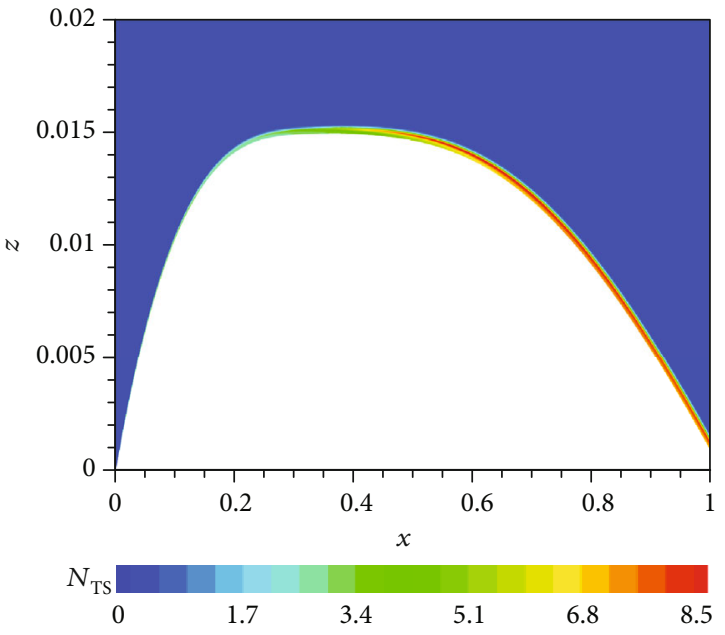

(a)

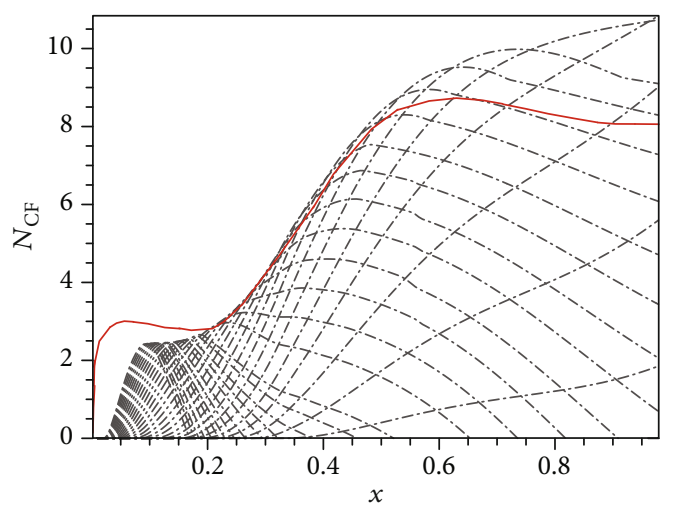

(b)

FIGURE 17: The predicted (a) $N_{\text {TS }}$ contour and (b) comparison with standard LST analysis results at $\operatorname{Re}=8.0 \times 10^{7} / \mathrm{m}$. 
On the whole, although the application scope is limited to supersonic configurations with sharp leading edge, all the formulations established in this model provide a good idea and a reasonable fundamental framework for the modeling of oblique T-S waves in supersonic boundary layers. The extensive validations at various Mach numbers, Reynolds numbers, and angles of attack are all in accord with the standard LST analysis results, which has proven that the present transport equation is constructed reasonably and correctly. As for the history effect term, it should be taken into account by a new transport equation in the next step.

\section{Data Availability}

The data used to support the findings of this study are available from the corresponding author upon request.

\section{Conflicts of Interest}

The authors declare that there is no conflict of interest regarding the publication of this paper.

\section{Acknowledgments}

The authors would like to thank $\mathrm{PhD}$ candidates Runjie Song from Department of Mechanics of Tianjin University and $\mathrm{Yu}$ Zhang from School of Aeronautics of Northwestern Polytechnical University for their valuable suggestions and discussions. This work is supported by the National Natural Science Foundation for Young Scholar of China (grant numbers 11602199 and 11802245).

\section{References}

[1] J. Xu, Z. Fu, J. Bai, Y. Zhang, Z. Duan, and Y. Zhang, "Study of boundary layer transition on supercritical natural laminar flow wing at high Reynolds number through wind tunnel experiment," Aerospace Science and Technology, vol. 80, pp. 221231, 2018.

[2] R. B. Langtry, F. R. Menter, S. R. Likki, Y. B. Suzen, P. G. Huang, and S. Völker, "A correlation-based transition model using local variables part I: model formulation," Journal of Turbomachinery, vol. 128, no. 3, pp. 413-422, 2004.

[3] R. B. Langtry, F. R. Menter, S. R. Likki, Y. B. Suzen, P. G. Huang, and S. Völker, "Correlation-based transition model using local variables part II: test cases and industrial applications," Journal of Turbomachinery, vol. 128, no. 3, pp. 423434, 2004.

[4] R. B. Langtry and F. R. Menter, "Correlation-based transition modeling for unstructured parallelized computational fluid dynamics codes," AIAA Journal, vol. 47, no. 12, pp. 28942906, 2009.

[5] D. K. Walters and J. H. Leylek, "Computational fluid dynamics study of wake-induced transition on a compressor-like flat plate," Journal of Turbomachinery, vol. 127, no. 1, pp. 52-63, 2005.

[6] K. D. Walters and D. Cokljat, "A three-equation eddy-viscosity model for Reynolds-averaged Navier-Stokes simulations of transitional flow," Journal of Fluids Engineering, vol. 130, no. 12, 2008.
[7] S. Fu and L. Wang, "RANS modeling of high-speed aerodynamic flow transition with consideration of stability theory," Progress in Aerospace Sciences, vol. 58, no. 2, pp. 36-59, 2013.

[8] J. Xu, J. Bai, L. Qiao, Y. Zhang, and Z. Fu, "Fully local formulation of a transition closure model for transitional flow simulations," AIAA Journal, vol. 54, no. 10, pp. 3015-3023, 2016.

[9] J. Xu, J. Bai, Z. Fu, L. Qiao, Y. Zhang, and J. Xu, "Parallel compatible transition closure model for high-speed transitional flow," AIAA Journal, vol. 55, no. 9, pp. 3040-3050, 2017.

[10] J. Xu, J. Bai, L. Qiao, and Y. Zhang, "Development of a computational fluid dynamics compatible mathematical model for boundary layer transitional flows in low-disturbance environment," Aerospace Science and Technology, vol. 86, pp. 487-496, 2019.

[11] J. K. Xu, J. Q. Bai, L. Qiao, and Y. Zhang, "Correlation-based transition transport modeling for simulating crossflow instabilities," Journal of Applied Fluid Mechanics, vol. 9, no. 5, pp. 2435-2442, 2016.

[12] A. M. O. Smith and N. Gamberoni, "Transition, pressure gradient and stability theory," in Douglas Aircraft Company Rept. ES-26388, Douglas Aircraft Company, El Segundo Division, Long Beach, CA, 1956.

[13] J. L. Van Ingen, "A suggested semi-empirical method for the calculation of the boundary layer transition region," in Technische Hogeschool Delft, Vliegtuigbouwkunde, Rapport VTH74, Delft University of Technology, Delft, The Netherlands, 1956.

[14] L. M. Mack, "Transition prediction and linear stability theory," In AGARD Laminar-Turbulent Transition 22 p (SEE N7814316 05-34), 1977.

[15] M. Drela and M. B. Giles, "Viscous-inviscid analysis of transonic and low Reynolds number airfoils," AIAA Journal, vol. 25, no. 10, pp. 1347-1355, 1987.

[16] M. Drela and H. Youngren, XFOIL 6.9 User Primer, Massachusetts Inst. of Technology, Cambridge, MA, 2001.

[17] N. Krimmelbein and A. Krumbein, "Automatic transition prediction for three-dimensional configurations with focus on industrial application," Journal of Aircraft, vol. 48, no. 6, pp. 1878-1887, 2011.

[18] G. Bégou, H. Deniau, O. Vermeersch, and G. Casalis, "Database approach for laminar-turbulent transition prediction: Navier-Stokes compatible reformulation," AIAA Journal, vol. 55, no. 11, pp. 3648-3660, 2017.

[19] L. Pascal, G. Delattre, H. Deniau, G. Bégou, and J. Cliquet, "Implementation of stability-based transition models by means of transport equations," in AIAA Aviation 2019 Forum, Dallas, Texas, June 2019.

[20] Y. Shi, R. Gross, C. A. Mader, and J. Martins, “Transition prediction in a RANS solver based on linear stability theory for complex three-dimensional configurations," in 2018 AIAA Aerospace Sciences Meeting, Kissimmee, Florida, January 2018.

[21] J. G. Coder and M. D. Maughmer, "Computational fluid dynamics compatible transition modeling using an amplification factor transport equation," AIAA Journal, vol. 52, no. 11, pp. 2506-2512, 2014.

[22] J. G. Coder, Enhancement of the amplification factor transport transition modeling framework, 55th AIAA Aerospace Sciences Meeting, Grapevine, Texas, 2017.

[23] J. G. Coder, Further development of the amplification factor transport transition model for aerodynamic flows, AIAA SciTech 2019 Forum, San Diego, California, 2019. 
[24] J. Xu, J. Bai, Y. Zhang, and L. Qiao, “Transition study of 3D aerodynamic configures using improved transport equations modeling," Chinese Journal of Aeronautics, vol. 29, no. 4, pp. 874-881, 2016.

[25] J. Xu, X. Han, L. Qiao, J. Bai, and Y. Zhang, "Fully local amplification factor transport equation for stationary crossflow instabilities," AIAA Journal, vol. 57, no. 7, pp. 2682-2693, 2019.

[26] L. M. Mack, "Boundary-layer linear stability theory," in Special Course on Stability and Transition of Laminar Flow, AGARD Rept, vol. 709, 1984.

[27] L. M. Mack, "Linear stability theory and the problem of supersonic boundary-layer transition," AIAA Journal, vol. 13, no. 3, pp. 278-289, 1975.

[28] T. Cebeci and J. Cousteix, Modeling and Computation of Boundary-Layer Flows, Springer, Berlin Heidelberg New York, 2005.

[29] I. Kroo and P. Sturdza, "Design-oriented aerodynamic analysis for supersonic laminar flow wings," in 41 st AIAA Aerospace Sciences Meeting \& Exhibit, Reno, NV., 2003.

[30] C. Grabe, S. Nie, and A. Krumbein, "Transition transport modeling for the prediction of crossflow transition," in 34th AIAA applied aerodynamics conference, 2016.

[31] G. Cheng, R. Nichols, K. Neroorkar, and P. Radhamony, "Validation and assessment of turbulence transition models," in 47th AIAA Aerospace Sciences Meeting including The New Horizons Forum and Aerospace Exposition, Orlando, Florida, 2009.

[32] J. Coder and M. Maughmer, "A CFD-compatible transition model using an amplification factor transport equation," in 51st AIAA Aerospace Sciences Meeting including the New Horizons Forum and Aerospace Exposition, 2013.

[33] T. Cebeci and K. Stewartson, "On stability and transition in three-dimensional flows," AIAA Journal, vol. 18, no. 4, pp. 398-405, 1980.

[34] S. L. Krist, R. T. Biedron, and C. L. Rumsey, CFL3D User's Manual (Version 5.0), NASA TM-1998-208444, 1998. 